\title{
Principles of Stacktivism
}

\section{Geert Lovink}

Institute of Network Cultures, Amsterdam University of Applied Sciences, The Netherlands, geert@xs4all.nl, https: / /www.networkcultures.org

\begin{abstract}
In this essay a new form of Internet activism is proposed: stacktivism. Building on hacktivist practices, this form of code and standard development as political struggle is envisioned to connect different layers of the techno-protological stack (also known as the Internet) in order build bridges between different, still isolated institutional levels and disciplinary practices such as grassroots wifi-access initiatives, interface design, geeks, computer scientists and governance experts. How do we envision a public stack that goes beyond the structures such ICANN, IETF and IGF that can take up the task to rebuild the Internet as a decentralized, federated, public infrastructure?
\end{abstract}

Keywords: Internet governance, Internet activism, public sphere, civil commons

"One of the last frontiers left for radical gesture is the imagination", David Wojnarowicz

Those that define Internet standards shape our thinking and hold the key to our freedom of communication - no trivial task. Yet tech policy is seen as boring: delegated to engineers, lawyers that represent corporations, research universities and ministries. In the now-past age of globalisation Internet governance and the machines that decide over regulations, protocols and the use of patents was outsourced to technocrats with a few "global civil society" NGOs agitating on the margins. However, in this age of $5 \mathrm{G}$ and TikTok conflicts, driven by calls for "techno sovereignty", there is no more consensus (and running code). In short, we demand protocols, not platforms. ${ }^{1}$ But who's going to get us there? Meet the stacktivists. ${ }^{2}$

Benjamin Bratton's The Stack, published in 2016 by MIT Press, can be useful to bounce ideas against when we want to define the state of the art in technology, urbanism, design and activism. ${ }^{3}$ As is often the case with today's speculative thinking - from accelerationists to Reza Negarestani - Bratton's proposed scenarios can go either way. The book stacks layers, one on top of the other, starting with Earth as the foundation, the first layer is occupied by Cloud, then City, Address, Interface with the User on top. As Marc Tuters describes in his review of the book, "The Stack model is in-

${ }^{1}$ See: https://knightcolumbia.org/content/protocols-not-platforms-a-technological-approachto-free-speech.

2 The term stacktivism was arguably first used for an unconference in London in 2013 and defined as "a term that attempts to give form to a critical conversation \& line of enquiry (infra-spection?) around infrastructure", https://stacktivism.com/unconference.

${ }^{3}$ Bratton, Benjamin H. 2016. The Stack, On Software and Sovereignty. Cambridge, MA: The MIT Press. I would like to thank Pit Schultz for the many conversations and email exchanges, with whom first notes for this essay were made. Also thanks to Antonia Majaca and Ned Rossiter for the conversations and feedback and Jack Wilson for the copy-editing. 
tended to include all technological systems as part of a singular planetary-scale computer, a kind of Spaceship Earth 2.0, updated to reflect the demands of the Anthropocene era". 4

Grand designs such as The Stack can be read as a proposition to connect the dots ${ }^{5}$ while also containing encrypted insights for the few "thoughtful men", known to be "careful readers". ${ }^{6}$ What's the purpose of obfuscated theories if not attracting groupies, creating an avant-garde cult aka lifestyle sect that's only accessible to initiated members who can decode the messages? Are we dealing here with meta-Marxism ${ }^{7}$ or a US globalist conspiracy theory? However, in these regressive, confused and turbulent times no one seems to sure. Obscure language and behaviour in the fields of politics and aesthetics can be interpreted either as a courageous refusal to conform to the dominant retrograde discourses or be read as straight out evidence of the status quo.

Stacktivism is not an Anti-Bratton (as in Friedrich Engels' Anti-Dühring), rather nonBratton as in non-fascist. Beyond good or evil, the media theory classic The Stack should be considered a worthy follow-up of Lev Manovich's 2001 The Language of New Media (both MIT Press classics that are attached to, but not necessarily conceptualised and written in San Diego): inspiring to disagree with. One can read The Stack as a Foucaudian toolkit that lifts out the useful parts, leaving the critique of Bratton's unreconstructed love for Carl Schmitt to others. It's easy to take apart Bratton's naïve dream of "planetary computation" populated by sci-fi species-beings while still enjoying the vast theory landscape he offers in this Magnum Opus.

Benjamin Bratton's recent activities as programme director at the Moscow based Strelka Institute include grand visions such as The Terraforming, an education project that is purposely designed with unclarity as the main feature ${ }^{8}$. At Strelka, the hyperspeculative overdrive tactic is used to overrule the pressing political topics of our time, including the financing of the centre itself by oligarchs and their alliances with the Kremlin. According to Wikipedia the program deals with "long-term urban futures in relation to technological, geographic and ecological complexities" ${ }^{\prime}$. We only need to follow the money to understand why Bratton was hired to keep politics out while hiding this strategy with dazzling jargon and aesthetics.

What we do not need is yet another Realpolitik or more violent globalist neo-liberal consensus. Our crumbling world is in urgent need of new vocabularies and visions. There will be no return to the old normal. But what happens when grandiose vistas block our view of the real existing interest groups and ideologies that feed - and feed off - contemporary theory production? What kind of politics of abstraction is going on here? There's a fine line between empowerment through knowledge and techno-obfuscation of a planetary engineering class in the making: digital Jesuits that do indeed instigate deep spiritual change of the power elites, yet hover above the geo-political trivialities of the day.

${ }^{4}$ http://computationalculture.net/scenario-theory-review-of-benjamin-h-bratton-the-stack-onsoftware-and-sovereigntyl.

${ }^{5}$ For example A Future for Intersectional Black Feminist Technology Studies by Safiya Umoja Noble.

${ }^{6}$ See Leo Strauss. 1952. Persecution and the Art of Writing. Chicago, IL: The University of Chicago Press. p. 25.

${ }^{7}$ https://medium.com/the-abs-tract-organization/the-abstraction-of-benjamin-bratton756c647ab6ec.

${ }^{8}$ https://theterraforming.strelka.com/.

9 https://en.wikipedia.org/wiki/Strelka Institute. 
What type of speculative thinking do we need in this disaster era of climate change, growing inequality, Black Lives Matter and real existing geo-politics? Where are our radical think tanks that go beyond the institutional policy limitations of scenario thinking (and their critics)? What's subversive and poetic weirdness today? Do we really have to first cross the muddy waters of Heidegger and Schmitt in order to get anywhere? Can post-colonial and post-gender futurism help us to liberate ourselves from the dark reactionary thought systems of the European $20^{\text {th }}$ century? What happens when all contingency planning of the past is shoved aside and institutional prediction industries are so easily unsettled by the intrusion of the unpredictable? In a turbulent world where the administration of the present is delegated to the dazed and confused, ideology design is up for grabs. Let's refine the art of strategic forecasting in these times of collapse while not being naïve about the collective power of "making worlds".

Lately, the concept of "the stack", once a technical insider term used amongst engineers and geeks ${ }^{10}$, has jumped context and transformed into a general container concept, in danger of becoming an empty signifier. As a meta-concept The Stack has been detached from its author and his Californian-nihilist program for the aspirational cool-crowd and turned into a symbol for the need to bring together interrelated crises, from climate change, inequality, Al and automation to covid-19. In Bratton's world, you sign up from the program and carry the card, otherwise the entry sign points to exit. No affect, behavioural noise or regional ambiguities please - we're performing Important Theory here. Perhaps this is a form of group therapy for the insecure? That's fine if you like the taste of testosterone in your milk shake.

This is the time to design one, two, three, indeed many stacks and not to dismiss the ambitious efforts of others because, after all, where are the European antidotes to Bratton or Zuboff? Europe tragically fails in the production of contemporary reference texts, both at the speculative and the critical level. While the late Bernard Stiegler comes in mind, a lot of translation work is still to be done in order to transform his philosophy of technology into workable programs decoupled from his often-obscure neologisms. For instance, where are the counterproposals of the crypto-blockchain system? The Bratton bible, written in the quasi-authoritarian voice of a Master Designer, can also be read from a grass-roots perspective and should be praised for its multi-disciplinary analysis of techno-social (power) practices. Why not be ambitious? There's a lot at stake. As a proposal, Bratton's reading of The Stack should be compared to Dante's hell, Sloterdijk's notion of the spheres, Deleuze and Guattari's Mille plateaux, Hui's cosmotechnics and Stiegler's The Age of Disruption. But instead of conducting hermeneutic exercises, the proposal here is to transplant the term into the hacktivist context and define the principles of "stacktivism": dancing stacks ${ }^{11}$.

${ }^{10}$ See for instance https://techterms.com/definition/stack. A classic description of a stack can be found in the Life After Google, written by right-wing techno-evangelist George Gilder, who comes up with a "seven-layer model of a hierarchical stack in which lower functions are controlled by higher functions. (Regnery Gateway, Washington DC, 2018, p. 162) with a physical layer, the datalink, the network layer, Internet protocols, a session layer and schemes for presentations and applications.

11 This essay can be read as a continuation of the Media-Network-Platform chapter in Geert Lovink. 2019. Sad by Design. London: Pluto Press, where I defined the vertically thinking stackivism as "infrastructural activism that is aware of multiple interconnected layers. This is hacktivism with a holistic awareness of the levels that exist above and below code" ( $p$. 74). 
We can also read The Stack as a pedagogical framework within the Bauhaus tradition as a proposal for a general design principle, as John Thackara has recently done, updating the Bauhaus foundation course for the age of global warming ${ }^{12}$. As an abstract model describing the architecture of the Internet, the stack provides us with a useful spatial division of layers such as protocols, data, applications and user interfaces. Bratton's notion of The Stack comes out of the US postmodern literary tradition of cognitive mapping (Jameson), which seeks to make intelligible (and containable) complex processes. Bratton combines this approach with decades long attempts to visualise the vertical integration of technologies drawn in 2D, with maps of networks that strive to capture relations between the different players. His aim is to produce a general network theory able to provide deeper insights in the dynamics of power: blowing up 2D tech engineering plans to a $3 \mathrm{D}$ dimension able to modulate planetary transformation.

Benjamin Bratton also invites us to think tech in relation to geo-politics and location. At the same time The Stack can be seen as method, a mechanism. However, the book is consciously vague about how material infrastructure and ideology relate. In the light of Trump, Putin and Xi Jinping, Bratton's global engineer seems a tragic, retrograde figure. At best The Stack works well as a multi-disciplinary guideline of past globalist techno-social practices that, ironically, have become outdated since 2016, the year of its publication and the year of Brexit and Trump. For all its ambition to delineate the geo-political contours of techno-operations supposedly occurring on a planetary scale, the book settles with an oddly depoliticised aesthetic imaginary.

How can we free up The Stack from its current confinements and turn into an improvised dance? Let's define a stacktivism, an active and reflective reading of stackson-the-move, that is not afraid of the subject (formerly known as user) and involves action, committed by confused, selfish, messy players. With this I mean grassroots interventions that do not take the current (Internet or IT infrastructure) stack as a given and turn the Will to Totality of the engineering class and their financial backers against itself. In comparison with the hacktivism and (tactical) media activism, stacktivism is indeed Hegelian in scope (Understanding Totality). It is confronting "das Ganze" and can be considered counter regressive as it takes into account the real-existing totality of today's interrelated tech-architectures as opposed to the shrinking paranoid world of the online self that is in constant danger of collapse under the weight of its own selfimage, surveillance, precarity and depression.

Niels ten Oever, Amsterdam-based Internet governance researcher and activist emphasises the importance of linking contexts and levels:

"The stack never was and never will be. The stack always was an abstraction, a story that was told to keep people working in an isolated manner, ensuring engineers stuck to their own layer. As long as you worked within your own parameters and delivered what the layer above and below you expected of you, you would not get into trouble. Stacktivism, on the other hand, works across the stack: it is a cross-stack collaboration, an attempt to realign and redesign the interfaces. Looking for interconnections and associations that cannot be drawn from above, that defy standardization. Interconnections that escape abstractions and stereotypes. They are established through dynamic and unpredictable handshakes: questions, answers, and re(-)cognition"13.

${ }^{12}$ http://thackara.com/notopic/what-should-a-bauhaus-foundation-course-be-like-today/.

13 Private email exchange, September 20, 2020. 
Stacktivism is ambivalent and struggles with totality, the global scale and the planetary whatever. Think big, but act in small steps, that's the motto. We Are Infrastructure. Stacktivism fights against the comfort of ignorance and tries hard to overcome the designed lure to drift off, hovering above it all in a subconscious fashion. While defining what stackitivism could become, it is good to keep mind that we're free to use Bratton's The Stack as a theory toolbox and not interpret it as a hermetic belief system. Designs can intermingle. In line with Bratton, stackivism claims to understand and oversee all levels, from the politics of code, algorithms and Al to the behavioural science manipulation of moods, interface design choices and is alert to $5 \mathrm{G}$ electronic smog, phishing emails, fake news and the other sleazy suggestions of your "friends". How about your bot sensibility? This hyperawareness comes at a high price. Not everyone is a stacktivist $:$

Traditionally, direct action has been put in opposition to the talk fest. When we act, we stop talking and start doing. In the context of hacktivism this means that we no longer consume but start to code in order to be able to hack into computer systems in order to make real, tangible changes in society. Like Robin Hood, let's define what stackivism-for-good could look like. How do we build rhizomatic links between global governance, protocol design, the ethics-without-consequences industry, code writing and investigative hacking? Who will be in charge of subversive foresight? Can we dream aloud together? How can delegate trust to our think tanks that work in the public interest?

Stacktivism is a sovereign attitude in that it is not begging for a correct form of representation and could be considered post-democratic and post-identity, yet remains always all-too-human. Inside Douglas Rushkoff's Team Human stacktivists take up the task of creating missing links: they are the meme sharers, idea connectors, intercultural fellow travellers, poly-disciplinary networkers. The social creation of new protocols remains an act of common decision. We are fighting at the conceptual forefront of tech. Nobody needs to give us permission. Unlike the tactical media interventions of the 1990s, stacktivism is - by definition- abstract and conceptual in nature, knowing that code is power and power is code. How to dismantle invisible power? Do we fight abstractions with abstractions, design with counter-designs?

According to Internet and civil society researcher Corinne Cath we could see stacktivism as a "playful human evolution of Bratton's concept of The Stack. It critiques its modular conception of world into discrete layers. To remedy this flattening, it calls for the inclusion of the inherent messiness of the Internet: the entangled basement wires, packets lost in translation, rugged governance cultures and the idiosyncratic usages of the humans who rely on it to function flawlessly"14. Francesca Musiani (CNRS, Paris) found the lessons of decentralisation telling:

"Decentralization often becomes a technical, political, economic and social aim in and of itself, reaching outside the 'hacker' circles of the early $p 2 p$ systems. However, this has had side effects. Decentralization has become an objective in and of itself, with little understanding of intent or assessment of actual effects. I love Phil Agre's 2003 observation in this respect when he said: 'Architecture is politics, but should not be understood as a substitute for politics'. Decentralized protocols are too readily assumed, because of their technical qualities, to bring about decentralized political, social and economic outcomes. A more fine-tuned

${ }^{14}$ Private email exchange, September 21, 2020. 
appreciation of the social dimensions of the stack is likely to improve things in this regard"15.

Media historicism (aka archaeology) has so far failed to develop critical concepts to understand the current situation, also known as platform capitalism. There is more to the Internet than the politics of the senses. Notation systems and perception are so $20^{\text {th }}$ century. What matters now is who owns the Internet in terms of data centres, cables and PR; and this is first and foremost a question of material analysis. A comparison with the Roman road system, as described in Innis's Empire and Communications is more relevant here ${ }^{16}$. Let's, for instance, investigate the relation between the modernist stack and the fuzzy post-modern cloud buzzword.

How does Bratton's design relate to recent proposals by stacktivists Francesca Bria and Evgeny Morozov for a European move towards "data sovereignty"? It's too easy to unmask Bratton as a Californian techno-solutionist. How much is gained by planting this (now effectively empty) label on him? To determine, to think technologically remains an utmost urgency and it is precisely the "stacking" of issues, factors and contexts that will bring us further into the constitutive force of technical systems. The spectacle of clashing characters should not distract us (in fact, the silo phantom, the silence and separation is, oddly, our main problem, in this hyperconnected world).

How does self-determination, for instance on a local level, relate to a visible decline in the consensus about the necessity to have global standards and global infrastructures? Is a fear of the Internet's Balkaniation justified? Right now, open architecture is the one principle that is in most danger. Open standards and protectionism do not go together. What would it mean if we gave up the planetary level and narrowed our collective imaginary to the geo-politics of competing regional empires? In a regulatory wave, platforms can be forced to fork, and, as a result of this, other layers of The Stack can be dragged with them. Many apps are already implicitly regional. Take the AngloSaxon bias of Google Books and contrast this to the (Siberian) multipolar Libgen library. The liberal consensus of some kind of harmonious multi-stakeholder alliance between "global civil society" and tech giants of "global governance as running code" has long lost any credibility. We're not only talking here about China's Great Firewall but also latest efforts in Russia, Turkey and Iran (not to mention USA's exceptionalism, which was one of the many causes of this development).

Does the one stack exist or should we rather speak of The Stacks, a rainbow of a thousand stacks, such as Tiziana Terranova's "red stack"17, the ancient blue stack of IBM and the green stack proposal that wants to tackle the massive energy use of the blockchain and data centres, including our own devices. And how about the European

${ }^{15}$ Private email exchange, October 16, 2020. See also Mélanie Dulong de Rosnay and Francesca Musiani: Alternatives for the Internet: A Journey into Decentralised Network Architectures and Information Commons, https://www.triple-c.at/index.php/tripleC/article/view/1201.

${ }^{16}$ Innis, Harold A., 1986. Empire and Communications, Toronto: Press Porcépic.

${ }^{17}$ According to Tiziana Terranova, the red stack "is a new nomos for the post-capitalist common. Materializing the "red stack" involves engaging with (at least) three levels of sociotechnical innovation: virtual money, social networks, and bio-hypermedia. These three levels are to be understood as interacting transversally and nonlinearly. They constitute a possible way to think about an infrastructure of autonomization linking together technology and subjectivation", http://effimera.org/red-stack-attack-algorithms-capital-and-the-automation-of-the-common-di-tiziana-terranoval. 
stack? In the aftermath of Snowden, the slogan "The Internet is Broken" started circulating, followed by Tim Berners Lee's proposals for an alternative architecture of the web, following the Cambridge Analytica/Facebook scandals of 2018/19.

What Bratton's definition of The Stack lacks is the society layer. We can only guess that his traditional US "globalist" upbringing is the cause of this mishap. A Thatcherite neo-liberal position perhaps lurks within his framework. Or should we rather think of an anarchist disgust with the state? The enlightened digital artist-engineer as Jesuit class? There is, for sure, more to say about this. Infrastructure does not equal society. A contemporary techno-Maoist slogan could be: There is no society, only infrastructure. There is no place either for the user as a civilian actor. What do we draw from this? As long as key layers are missing in such analyses, we can't really draw new relations between them. After all, nothing only connects with nothing. This is why some in the context of art and hacktivism have proposed redesigning Bratton's scheme as a "public stack"18.

We need to define new forms of collective action that some call the commons that is defined by the ability to act together. The design question here is what comes next after the model of social networks, which has been so compromised and overshadowed by the social media monopolies. This is a digital commons in which collective forms of money is included, a redistribution of wealth that has been produced together and should never again be allowed to be expropriated. We need to collectivise our knowledge and learn from the mistakes that were made in projects such as Wikipedia and Creative Commons, but also of the self-centric notion of free software as promoted by Richard Stallman, who could only think in terms of individual freedom of the singleuser-as-programmer - until his 2019 downfall.

What Bratton's static metaphysical view in particular lacks is the role of actors (and their interests, ideologies). Instead of trashing the stack, the proposition here is to make the model more dynamic (or dialectical) by introducing stackivism. Let's define stacktivism as a form of Internet activism that no longer bothers with the distractive noise on social media channels and dares to dig deeper in order to make a real difference. Instead of talking only about upload filters, fake news or the deployment of cheap online moderation armies, we are working on a next Internet. The charm of protocoldriven direct action or stacktivism is that it goes both up (from network to platform to stack) and down (protocols, data centres, cables), at the same time. The Internet is more than social media, more than you and your app. This may sound like a simple, self-evident slogan but the integral practice-based vision of stacktivism is a promising one, beyond techno-solutionism and it critics, the liberal-tech engineering status quo procedures, the discontent offline romanticism, liberal privacy concerns, legalistic NGO approaches and the after-the-fact Academic Truth that confines itself to the closed monads of peer-review journals.

Stacktivism embodies Adorno's critique of totality as a lie while climbing up the abstraction ladder in order to enjoy the view. Digitisation Takes Command. The stacktivist dilemma is a classic one: How can the multitudes gain power while pulverising power at the same time? The digital is now an encompassing global sphere. Is this dark enlightenment in action? In this light, how should we judge the Will to Stack? Dare to think in term of political strategies when talking about cosmotechnics (or cosmic networks, for that matter). We've left the era of technology-as-tool far behind us. The

${ }^{18}$ Public stack was the name of a boat trip workshop, held in Amsterdam, June 2018, organized by Waag: https://waag.org/nl/event/public-stack-summit. 
nasty feedback machines strike back and try to corner us, suppressing our desires and needs, even without us noticing the closing down of communication and expression.

Can The Stack (formerly known as the Internet) only be understood in its totality once it has fallen from its unity and been reduced to fragments (read: geo-political blocks and national webs)? Can we be global in scope on the protocol level, yet act locally in networks of strong-ties? Is it worth to think of cosmotechnics-for-good? Stealing code from the rich and inserting into networks of the poor, in the spirit of Aaron Schwartz and Anonymous' SkyNet? Do you still believe that another WikiLeaks is possible, beyond the focus on celebrity? Let's upgrade and broaden the vision how the fight against moral injustices could look like in the age of geo-political cyberwarfare and attacks on our critical infrastructure, not just the Internet but water, gas, electricity, bridges and hospitals. These are The Stacks of the People, and we'll better not be naïve about their vulnerability. We depend on The Stack. Making visible and defending critical public infrastructure could be one of the many tasks of stacktivism.

This leaves us with the question how to organise strategic forecasting in times of collapse. How can we bring together new forms of collective intelligence that are truly planetary in nature, which is to say conflictual and variegated, and not merely designed to replicate Western policy production? Call them organised networks or think tanks, we're gathering in a closed forum, on Telegram, Mastodon or Signal in order to get things done, overcoming the divisions that aren't ours. In theory we have all the communication skills, tools and ideas, yet we often do not know how to organise ourselves outside of surveillance capitalism and state control. Ni Zuckerberg, ni Xi Jinping ${ }^{19}$. How can we redistribute critical resources and talents? The need to bring together different and messy idioms of knowledge (technical, spiritual, cultural, political) is widely felt. What we will do next is act, together. What we need are simple, appealing images, models that bring people together to act. In this sense the "stack" motive can be the technical (at first equally unsexy) equivalent of Kate Raeworth's donut ${ }^{20}$. See the proposed stacktivism as one of many options, knowing that distributed forms of collective design will remake life from swamps.

\section{References}

Bratton, Benjamin H. 2016. The Stack, On Software and Sovereignty, Cambridge, MA: The MIT Press.

Gilder, George. 2018. Life After Google, The Fall of Big Data and the Rise of the Blockchain Economy, Washington, DC: Regnery Gateway.

Innes, Harold A. 1986. Empire and Communications. Toronto: Press Porcépic.

Mueller, Milton. 2017. Will the Internet Fragment? Sovereignty, Globalization, and Cyberspace. Cambridge, MA: The MIT Press.

Lovink, Geert. 2019. Sad by Design: On Platform Nihilism. London: Pluto Press.

Strauss, Leo. 1952. Persecution and the Art of Writing. Chicago, IL: The University of Chicago Press.

19 "If Internet users form a community with its own interests, incipient identity, and modes of living together, it doesn't matter whether existing sovereigns currently have the power to impose their rules on them. What matters is whether they can be organized to assert, and gain, their independence from those rules, or to force concessions and adjustment upon the old order." Mueller, Milton, 2017. Will the Internet Fragment? Cambridge (Mass.), MIT Press, p. 150. For stacktivists, the old order is symbolized by Silicon Valley and the Chinese Communist Party with Foxconn factories as synthesis.

${ }^{20}$ https://www.kateraworth.com/doughnut/. Raeworth is using the term networks. 


\section{About the Author}

Geert Lovink

Geert Lovink is a Dutch media theorist, internet critic and author of Uncanny Networks (2002), Dark Fiber (2002), My First Recession (2003), Zero Comments (2007), Networks Without a Cause (2012), Social Media Abyss (2016), Organisation after Social Media (with Ned Rossiter, 2018) and Sad by Design (2019). In 2004 he founded the Institute of Network Cultures at the Amsterdam University of Applied Sciences. His centre organises conferences, workshops, publications and research networks such as Video Vortex (online video), Unlike Us (alternatives in social media), Critical Point of View (Wikipedia), Society of the Query (the culture of search) and MoneyLab (internet-based revenue models in the arts). Recent projects deal with digital publishing, the future of art criticism and tactical visual culture. 